\title{
Perception of the Psychosocial Aspects of Subfertility by Parents Following Successful Medically Assisted Conception: A Qualitative Study
}

\author{
J. Catja Warmelink1,2, Janiek M. Meijer², Nienke Mulder², Sybren Mulder², Mirjam T. van Lohuizen² \\ ${ }^{1}$ Department of Midwifery Science, AVAG and the EMGO Institute for Health and Care Research, VU University Medical Centre, \\ Amsterdam, The Netherlands \\ ${ }^{2}$ Midwifery Academy Amsterdam Groningen, Groningen, The Netherlands \\ Email: catja.warmelink@inholland.nl,janiek_meijer92@hotmail.com,nien_mulder@hotmail.com,sybrenmulder@gmail.com, \\ mirjam.vanlohuizen@inholland.nl
}

How to cite this paper: Warmelink, J.C., Meijer, J.M., Mulder, N., Mulder, S. and van Lohuizen, M.T. (2016) Perception of the Psychosocial Aspects of Subfertility by Parents Following Successful Medically Assisted Conception: A Qualitative Study. Open Journa of Obstetrics and Gynecology, 6, 830-845. http://dx.doi.org/10.4236/ojog.2016.613101

Received: October 21, 2016

Accepted: December 5, 2016

Published: December 8, 2016

Copyright $\odot 2016$ by authors and Scientific Research Publishing Inc. This work is licensed under the Creative Commons Attribution International License (CC BY 4.0).

http://creativecommons.org/licenses/by/4.0/

\section{Abstract}

Nearly $5 \%$ of new-borns in the Netherlands are now born following Medically Assisted Conception (MAC), a steadily increasing number. Our qualitative study explored the subjective impact of subfertility and fertility treatment for parents who successfully achieve pregnancy following MAC and make health professionals more aware of the psychological needs of those clients. The study was based on the constructive/interpretative paradigm using a constant comparison/grounded theory design. Two men and nine women in the Netherlands who conceived as a result of MAC were interviewed in 2011. Our findings show that MAC-parents were exposed to a range of emotions such as disappointment, hope and uncertainty during the subfertile period, and these feelings were even felt after successful fertility treatment. The relationship and social support from friends and others in the same position were very important. Regarding the relationship with the partner during the subfertile period, the main thing the couple have to do is to keep talking with one another. Although they did not always agree on all issues, it was found that maintaining the communication strengthened the links between them by the end of the process. We concluded that the feelings and emotions during fertility treatment play a big role during the subfertile period and remain important during pregnancy and even after childbirth. Subfertile clients want maternity care providers to ask those who successfully achieve pregnancy following MAC about their experiences during fertility treatment, check that they still are receiving adequate social support, and involve the partner in prenatal checks. 


\section{Keywords}

Subfertility, Fertility Treatment, Maternity Care, Perception, Qualitative Research

\section{Introduction}

The current prevalence of subfertility (not being able to get pregnant (conceive) after one year of regular, unprotected sex) is estimated to be around $9 \%$ worldwide for women aged 20 - 44 [1]. Medically assisted conception (MAC) is becoming an increasingly more common treatment option for women and couples who experience subfertility, especially in Europe [1]. At least $4.3 \%$ of all births in the Netherlands result from MAC [2]. In the Netherlands, pregnancy after MAC is considered "normal" with no indication for increased obstetric risk. Therefore, a MAC-pregnancy can be monitored by a primary care midwife [3].

Subfertility and subsequent fertility treatments in general can have strong negative psychosocial consequences, although Paul et al. [4] did find in a cross-sectional study that some of the 121 studied individuals in the USA experiences this part of their life as a period of personal growth. The negative consequences found in many studies and reviews included increased levels of stress, confusion and anxiety [5] [6] [7], decreased satisfaction with the couples' relationship and sexuality [8] [9], decreased satisfaction with social life and, in unsuccessful treatments, hampered grieving [10] [11] and lasting sadness [12]. These negative consequences are found in both men and women, and while some authors suggest these consequences may be somewhat stronger in women [8] [13] [14], others did not [12] [15]. A successful fertility treatment does not resolve all negativity, as parents who conceived through fertility treatment had higher levels of anxiety in early pregnancy [5] [16] and perceived pregnancy as being more risky and demanding [17] [18].

The pervasiveness of the psychosocial impact of subfertility and fertility treatments, has led some authors to concluding that midwives and other maternity care providers need to know about their clients' experience during a possible previous period of subfertility if they are to plan perinatal care effectively [19]. Awareness of subfertility issues [20] [21] [22], knowledge on (the impact of) subfertility and subfertility treatments [23] and understanding of the needs of clients who successfully conceive after treatment [16] [17] [24] [25] [26] may be present for fertility staff in hospitals, this information have been found lacking in midwifery care practice in community. Increasing knowledge and awareness of the client's experiences through research could bring perinatal care more in line with the needs of couples who have undergone successful fertility treatment. This study used data from a larger qualitative research on the impact of subfertility and MAC-pregnancies on the perspectives of pregnancy and birth [24].

The research question addressed in the current paper was: How do parents after a MAC-assisted pregnancy describe the psychosocial impact of the subfertile period and fertility treatments? The aim is to make health professionals who provide midwifery 
care for people who have conceived with MAC more aware of any specific psychosocial need they might have as a result of the experience of infertility and fertility treatment.

\section{Methods}

\subsection{Study Design}

This qualitative study was undertaken using an interpretivist/constructivist paradigm and a constant comparison/grounded theory design [27] [28] with semi-structured, indepth open interviews to explore the impact of subfertility and fertility treatment for parents who successfully achieve pregnancy following fertility treatment. The COREQ checklist [29] was used to ensure that our study complied with the criteria for qualitative research. We intended to interview until we reached saturation of concepts.

\subsection{Data Collection}

The participants-who have conceived and given birth as a result of fertility treatmentwere recruited via an announcement on an internet forum for people with fertility problems and via snow-ball sampling. Nine interviews with eleven participants were held. Two couples were interviewed at home in Groningen in the spring of 2011 by final year midwifery students (student group A) who had received a five-day training on interviewing and qualitative research. After the decision to continue this study, seven interviews with participants outside Groningen were held by phone by CW (psychologist) in November 2011. All interviewees had gone through a period of subfertility and finally became pregnant after fertility treatment. The interviewers did not know the interviewees. There were two other persons interested in participating in the study, but they dropped out for unknown reasons before the interviews were held.

Prior to data collection, the topic list and semi-structured interviewing method were tested in a pilot interview with a midwife lecturer. The topic list shown in Table 1 was used to ensure internal consistency of the interviews. The follow-up questions depended on what the interviewees said. All interviews were recorded on tape, and lasted 55 minutes on average (range: 28 - 91 minutes). Participants were encouraged to speak freely about their experiences before, during and after pregnancy in a single interview. The interviewers stressed their neutrality by exploring both positive and negative remarks of participants. At the conclusion of each interview the participants were invited to provide feedback on the interview and to verify a short oral summary. Directly after

Table 1. Topic list for interviews with parents who have conceived as a result of fertility treatment.

Fertility history (context of desire to conceive, fertility treatment, gravidity, miscarriages, surrogate pregnancies, abortions)

Gynaecological \& obstetric history (parity, details of past pregnancies)

What was your experience during your period of subfertility?

What role did feelings and emotions play during the period when you were trying to become pregnant?

How did the people close to you react to your feelings and emotions during fertility treatment? 
an interview the interviewers evaluated their findings and formulated areas that called for more in-depth exploration in the next interview related with the current study, following the constant comparison/grounded theory design.

\subsection{Data Analysis}

All nine interview recordings were transcribed verbatim. The transcripts were initially read separately by JM, NM and CW and text segments were selected on relevance to the research question. Data were then categorized into themes by each researcher, using content analysis [27]. The interviews were first open coded (labelling), axial coded (categorized) and then selectively coded (thematically). The analyses were performed by CW (psychologist), JM and NM (student midwives), with consensus reached on the findings and with reflections on the research process and the role of the researchers. Transcripts were coded by each researcher independently, and the code trees generated were in agreement with each other. Examples of the analytical coding process are shown in Table 2. All codes, categories and themes found were then arranged in a code tree (Figure 1). The analysis indicated data saturation, which means that the inclusion of further data would probably not have resulted in the identification of new themes. Quotes were translated into English by an accredited translator. To assess the credibility of our findings, the final subthemes and main themes were discussed in a group session of health care professionals at a conference, with midwifery lecturers and with a midwifery consultant at a fertility centre.

\subsection{Ethical Considerations}

This study was approved for research purposes by the scientific committee of our institute (WC2011-005) and supported by patient organisation Freya. All interviewees received written information by email and verbal information about aim and content of the interviews, and the interviewees gave verbal informed consent to audio taped interviews. All participants were assured of anonymity and confidentiality and that they could freely withdraw from the study at any time. All data were anonymized. Each participant was given the opportunity to read their transcript and a draft version of this article. No further comments were returned.

\section{Results}

We held interviews with participants from different parts of the Netherlands (north, central, south). Table 3 presents the participants' characteristics. The average age of the

Table 2. Example of coding process; emotions during MAC.

\begin{tabular}{|c|c|c|c|}
\hline $1^{\text {st }}$ level & $2^{\text {nd }}$ level & $3^{\text {rd }}$ level & $4^{\text {th }}$ level \\
\hline Fragment & Labelling & Category & Theme \\
\hline Bertha p.4.: "Such a range of different feelings. & Angry & & \\
\hline Angry one moment, sad the next, and finally & Sad & Feeling and emotions & Emotions \\
\hline indifferent-you just say, well that's how it goes. & Indifferent & with MAC & during MAC \\
\hline (..) A bit of an emotional rollercoaster." & Emotional rollercoaster & & \\
\hline
\end{tabular}




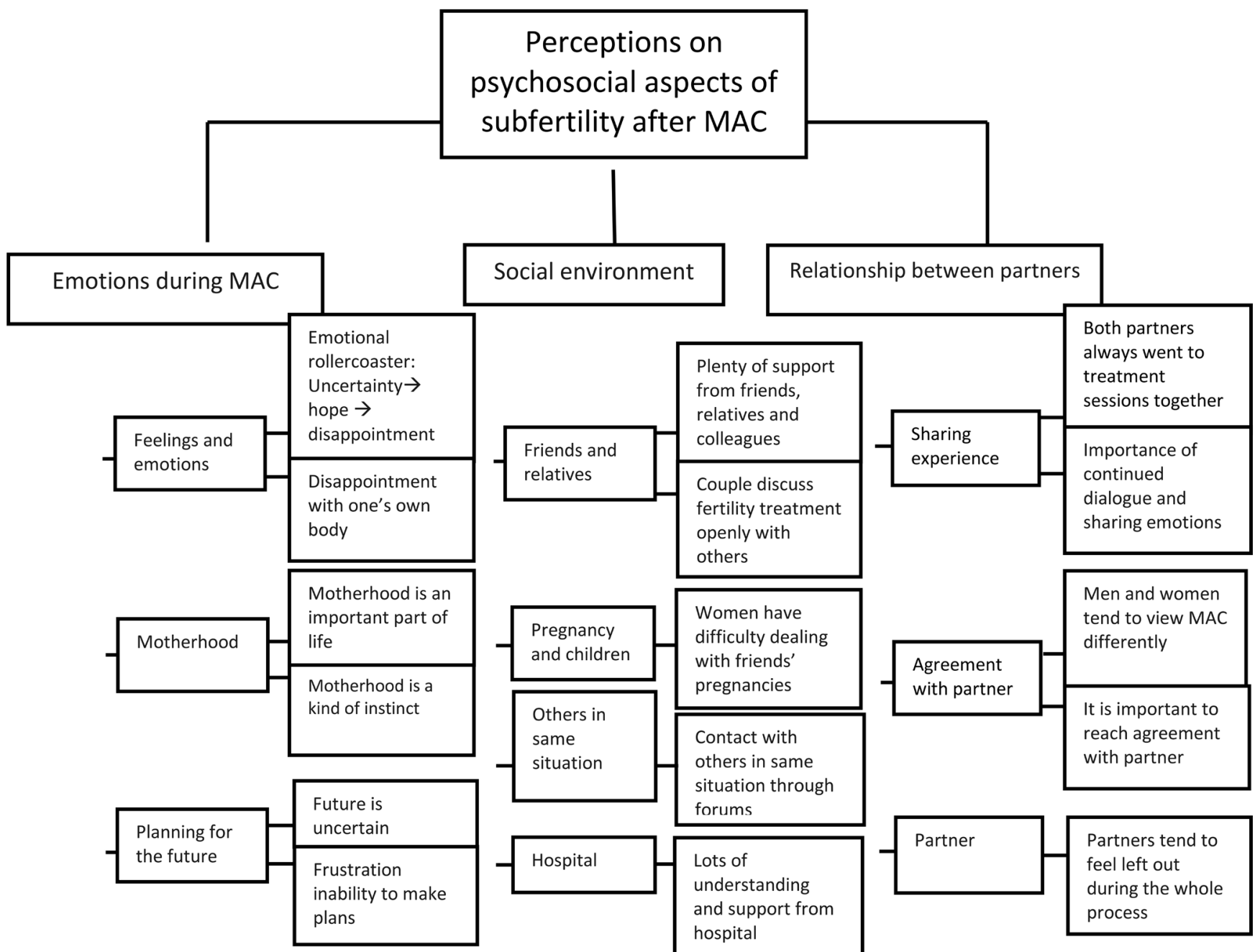

Figure 1. Schematic representation of the results.

women was 34.1 years (range 32 - 38 years) and the average age of the men was 33.5 years (range 32 - 35 years). The majority of the participants had waited two years or more to get pregnant (range 6 months- 5 years). The cause of subfertility was attributed to the woman $(\mathrm{n}=2)$, the man $(\mathrm{n}=4)$, both partners $(\mathrm{n}=1)$ or cause unknown $(\mathrm{n}=2)$. Different fertility treatments were used, like IntraUterine Insemination (IUI), IVF, ICSI and donor insemination (DI).

The perceptions on psychosocial aspects of subfertility of parents who have conceived and given birth as a result of fertility treatment could be categorised into three main themes.

1) Emotions during MAC, describing the feelings and emotions associated with fertility treatment, motherhood and getting on with life after fertility treatment.

2) Social environment, describing the interaction with friends and relatives with other pregnant women and their children, and with others in the same situation and the hospital. 
Table 3. Characteristics of interviewees.

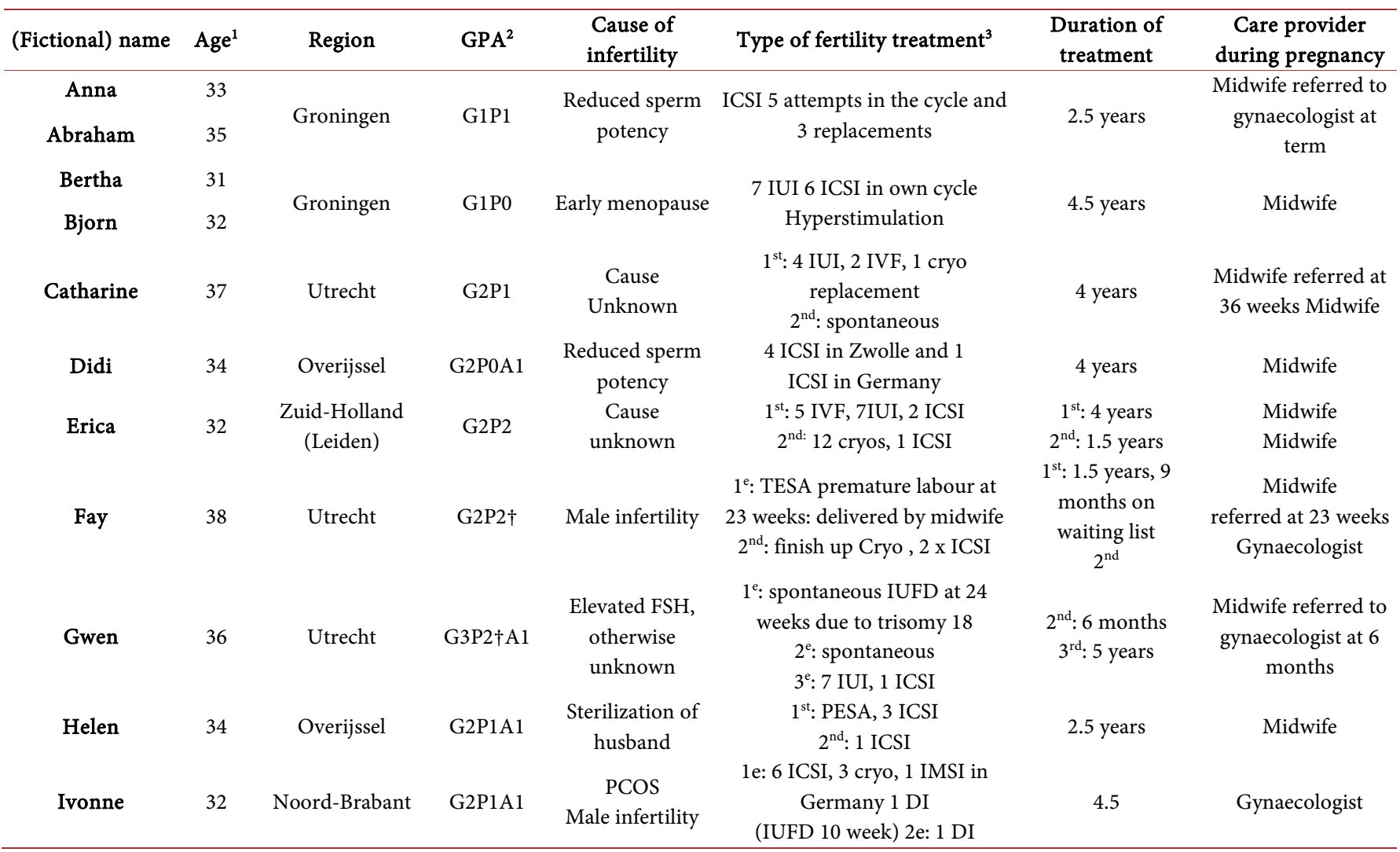

${ }^{1}$ At time of interview, ${ }^{2} \mathrm{G}=$ gravidity, $\mathrm{P}=$ parity $\mathrm{A}=$ No. of abortions, ${ }^{3} \mathrm{Cryo}=$ cryopreservation, $\mathrm{DI}=$ donor insemination, ICSI $=$ intracytoplasmic sperm injection, IMSI intracytoplasmic morphologically selected sperm Injection IUFD = intrauterine Foetal Death, IUI = intrauterine insemination, IVF $=$ in vitro fertilization, $\mathrm{PCOS}=$ polyCysteus ovarium syndroom. $\mathrm{PESA}=$ percutaneous epididymal sperm aspiration, TESA = testicular sperm extraction.

3) The couple's relationship, describing the importance of communication, the importance of reaching agreement on key issues and the partner's perception of the whole fertility treatment process.

\subsection{Emotions during MAC}

\subsubsection{Feelings and emotions with MAC}

Fertility treatment gives rise to a variety of feelings and emotions to the interviewees, irrespective of the type or length of fertility treatment involved. The interviewees experienced MAC as time-consuming and frustrating (Table 4), largely due to the alternation of hope and disappointment in the course of the treatment. The women regarded their wish to have children as a very natural one, and that failure to conceive by natural means led them to feel disappointed in their own bodies. The interviewees further frequently stated that they overcame this feeling of disappointment at a given moment (Table 4). When the course of treatment was completed, women tended to feel very uncertain, while at the same time hoping for a good result. They could hardly wait to have the test that would tell them whether the treatment had been successful. However, a negative test result led to disappointment and loss of all the hope that had been 
Table 4. Emotions during MAC: feelings and emotions with MAC-quotes of interviewees.

Anna (p. 2): "You know in advance that it's not going to be an enjoyable experience, and you take that into account, but still ... all that waiting, the whole process takes so long, it's just very frustrating."

Anna (p. 13): No, I don't think I really felt like that. Of course, it's disappointing but you develop immunity to disappointment."

Bertha (p. 4): "Such a range of different feelings. Angry one moment, sad the next, and finally indifferent-you just say, well that's how it goes."

built up. In brief, the parents experienced a whole range of conflicting emotions during the subfertile period (Table 4). These conflicting emotions could, among other reasons, give rise to doubt about continuing treatment.

\subsubsection{Motherhood}

Nevertheless, motherhood seemed to be so important for all women that none actually stopped treatment. One of the reasons was that motherhood is such a basic instinct to these women that they cannot imagine life without it (Table 5). They could not bear the idea of never being able to conceive once they had set their mind on it. This topic came up repeatedly in our study, indicating that women regard motherhood as an essential part of their life (Table 5). They felt that having a baby is an integral part of life. Some felt that the failure to have a baby would mean the end of their life.

\subsubsection{Planning for the Future}

Sadness was followed by frustration, when interviewees found that they could not plan for the future. Participants found in very difficult to make practical decisions, because they did not know what their life would be like in the future (Table 6).

\subsection{Social Environment}

\subsubsection{Friends and Relatives}

Couples who were prepared to talk openly about their fertility treatment received a lot of social support and involvement from the people around them (Table 7). Just having someone who was prepared to listen and to whom they could tell their story was regarded as important in this respect. Friends who had been through the same kind of experience gave a lot of understanding and sympathy.

\subsubsection{Pregnancy and Children}

Interviewees sometimes found it difficult to deal with the pregnancy of their friends who had conceived naturally (Table 8). Mothers-to-be and their partners spoke less about their pregnancy and showed less interest in details of the fertility treatment when they had passed on to the next phase, that of "pregnancy and having children". This shift in focus could lead to tensions on both sides. Nevertheless, it appeared from the interviews that no friendships were broken, even though some interviewees found it quite painful to see their friends' new babies.

\subsubsection{Other People in the Same Position}

The contact with people in the same position through Internet forums or in their own social network, and the recognition and understanding this gave, was particularly welcome (Table 9). The feeling that they were not alone in this experience was reassuring, 
Table 5. Emotions during MAC: motherhood-quotes of interviewees.

Erica (p. 22): "Yes, it's a kind of basic instinct, I think, the wish to have a baby whatever happens."

Catharine (p. 17): "The possibility that increased with every course of treatment you had-at least, that's how you feel-that you would never have the baby you dreamed of. I really couldn't imagine a life without motherhood. It was like a huge monster creeping up on me, and it would leave a big black hole behind: I couldn't imagine what would happen if we were in that situation."

Erica (p. 21): "It's such a big part of your life, isn't it? I just couldn't be without it."

Table 6. Emotions during MAC: Planning for the future-quotes of interviewees.

Catharine (p. 15): "At a given moment I needed to make up my mind about study, work and all those sorts of things. But it's impossible to make decisions if you don't know what's going to happen in the years to come."

Table 7. Social environment: friends and relatives-quotes of interviewees.

Bertha (p. 3): "We always spoke very openly about it to everyone-even my boss, or colleagues. You simply need to say, we've just got back from the hospital. Being perfectly honest with everyone is definitely the best course of action."

Table 8. Social environment: pregnancy and children-quotes of interviewees.

Didi (p. 4): "But then, suppose your friends manage to get pregnant. That can be really difficult to deal with. Of course, you're glad for them, but you're longing to be in the same position yourself. And you see a big change in them: they're going to be parents, they're going to have a baby, and they're moving on to a whole new phase in their life."

Bjorn and Bertha (p. 5): "She said she was pregnant, and the baby was giving her trouble. Well, you wish your friends would shut up about that kind of thing. I mean, it's not very tactful to say 'Oh, the baby's giving me such terrible lower back pain' when you know that I'm thinking I'd give anything to have lower back pain if I knew that I would be expecting a baby at the end of it."

Table 9. Social environment: contact with other people in the same position-quotes of interviewees.

Ivonne (p. 15): "One thing I particularly appreciated all those years was being on a forum that brought me into contact with all kinds of people in a similar situation. I was very glad of the understanding these other people showed. (...) We were all in the same boat. I was always very glad to be able to talk about it."

and sometimes engendered more trust in the treatment. The others were 'experts by experience' and could give good advices about treatments, etc.

\subsubsection{Hospital}

One interview underlined the support and understanding offered to the couple by hospital staff. They were ready at all times to do what was needed, not only for the woman but also for her partner (Table 10). This interview also stressed the support available from a medical psychologist (Table 10).

\subsection{Relationship between Partners}

\subsubsection{Sharing Experience}

A recurrent theme in the interviews was that the couple went through the fertility treatment together, and shared various feelings and emotions in the process (Table 11). It was important to continue the dialogue, to give one another space to express emotions, discuss these emotions and sometimes to distance themselves for a moment. The couples really formed a team during the treatment process, got to know one another better and felt the strength that comes from unity. Women did not feel alone, because their partners always accompanied them to the treatment sessions.

\subsubsection{Need for Agreement between Partners}

It was important for couples to discuss their different views of the treatment and to try 
Table 10. Social environment: hospital—quotes of interviewees.

Ivonne (p. 15): "They also always explained everything they were doing in great detail. This emphasis on the procedure gave me a lot of confidence in the treatment, and they always asked how I was doing, and they asked my husband too. You don't get that degree of attention everywhere, so I always appreciated the fact that they were like that at the hospital in Breda."

Ivonne (p. 5): "I really got a lot out of it. I went to see her every 6 to 8 weeks or so, and she always laid her fingers on the painful points as it were, and on the things I was unconsciously concealing a bit."

Table 11. Relationship between partners-quotes of interviewees.

Abraham (p. 4): "I always had the feeling that we experienced everything as a unit. Of course, the physical aspects really only concerned her, but we had agreed to do everything together as much as possible, so even when she was being treated I was always there."

Didi (p. 4): "As long as you have the same targets in your sights, as long as you say we'll do everything together, everything possible, that unity gives you strength.”

Table 12. Relationship: need for agreement between partners-quotes of interviewees.

Bertha and Bjorn (p. 5.): "I have noticed that you experience the whole process differently from me and I experience it differently from you; and then the assumptions we make, you know ... you have a great tendency to say she's sad, I'm sad so she must be too, these processes don't run in parallel.(.) And then again, the same emotion can be expressed in different ways."

Didi (p. 4): "If one partner sets a limit and says I'm going to stop after five treatments for example, then you've got a problem in my opinion. I really had to work hard to get my husband to come to Germany with me. For the fifth treatment session, because he'd really had enough by that time."

Catherina (p. 15): "Well, you know, these treatments are often more of a woman thing than a man thing."

to reach agreement on this point. In many cases, the two partners expressed the same emotion in a different way, and then it was important to reach a common expression of these emotions (Table 12). In some cases, differences in views of the treatment could lead to conflicts between the partners. Two women pointed out that their views on the treatment were quite different from those of their partners (Table 12).

\subsubsection{Partner Powerless}

A majority of partners always accompanied the woman to a consultation. Feelings of powerlessness during the treatment were often expressed. The partners did their best to understand what was going on during the treatment (Table 13). The partner was often the one who wanted to stop the treatment first, because he couldn't stand the emotional strain and had lost hope in a good result. One woman stated that her partner found it terrible to see her suffer so.

\section{Discussion}

The present study was aimed at exploring the perceptions of the psychosocial aspects of subfertility in retrospect by Dutch parents who achieved a successful medically assisted conception. There is a psychological legacy of the experience of infertility and infertility treatment which can make people psychologically vulnerable during pregnancy and after birth so heightened awareness of this among maternity care providers would be welcome.

\subsection{Comparison with the Existing Literature}

Fertility treatment for our participants was associated with a range of negative emotions, which is consistent with earlier literature [6] [23] [30] [31] [32]. In addition our 
Table 13. Relationship with partner-quotes of interviewees.

Bjorn (p. 6): “Well, I was nearly always there too, I went with her. You can't do much, but at least you're there. But it's not my body. That's even more the case than in a pregnancy. There too, you're just standing around with nothing to do. (..) You can try to understand what's going on, to follow the procedure, but sometimes you simply can't. Especially when they inject those hormones, I sometimes have absolutely no idea what's going on. Then you may have to say, I don't understand why, but they're giving her hormones."

Erica (p. 20): "He hated to see me suffer like that. (..) You could see him thinking, I just want it to stop. For your sake as well, but simply because ... It's just so terrible."

participants described positive emotions that could occur, especially hope. It seems that particularly the alternation of hope with disappointment and stress is what makes the fertility treatments so emotionally taxing. The women involved also lose much of their self-confidence, and feel that they can no longer trust their own body. Couples and women were exposed to a whole range of emotions during the subfertile period, and these feelings were even felt after successful fertility treatment. The feelings and emotions which played a role during the subfertile period and fertility treatment might be only incompletely resolved and thus persist for many years, even after pregnancy.

Our analysis showed that the women we interviewed regarded motherhood as a kind of basic instinct and they could not imagine life without children. This may be one of the reasons why none of our interviewees decided to stop their treatments. This influence of the idea of motherhood on the perception of subfertility concur with the review by Greil et al. [33]. On the other hand, if they had stopped treatment, they could not have been in our study anyway.

Like ESHRE [23], Wilkes et al. [34] and Martins et al. [35], our study shows that understanding, support and the willingness to listen can have an important impact on the mental well-being of subfertile people. We found in our study that participants have difficulty dealing with the spontaneous pregnancy of their friends; friends who then advance into a new phase of life associated with pregnancy and childbirth. In fact, both the subfertile woman and her pregnant friend may find it difficult to respond positively to this situation. Unlike Wilkes et al. [34], however, we did not find that this seriously impaired the friendships.

One woman from our study consulted a medical psychologist and found this very helpful. Boivin, et al. [30] and Péloquin [8] confirmed that talks with a psychologist help to reduce stress. The role of peer-support through internet forums is fairly new to the literature and can reflect the emerging role of internet in health-related behaviours. Particularly the contact with peers who are further in the treatment process may be very helpful and health professionals can provide information about online psychosocial care options, such as contact details of online support groups, or infertility counselling, or psychotherapy [23]. Our interviewees stated that they got a lot of recognition and understanding from people in the same situation on internet forums, and that they appreciated this. However, the cultural context where the study was conducted and the infertility history of the participants need to be taken into account, when interpreting their openness in sharing the infertility experience with peers and relatives.

Similar to the findings of Wirtberg et al. [6] and Wilkes et al. [34], our study underlined the importance of a good relationship with the partner. Our findings stress the 
powerlessness of the man as a source of tension. Maintaining communication and giving one another leeway to express the same emotions in different ways were recurrent topics in the interviews. Wilkes et al. [34] and Klock [36] also found that couples were stronger and could cope with stressful situations better if they were united. We found that the partners did their best to be there at every treatment session, and to understand what was going on. Like Schmidt, et al. [9], our study revealed that joint attendance at treatment sessions sometimes improved the relationship between the members of a couple because they got to know one another better and built up a real team spirit.

\subsection{Strengths and Limitations}

One of the strengths of this study is its originality. To the best of our knowledge, this study is the first to explore the clients' perception of subfertility following successful assisted conception in the Netherlands, where a MAC pregnancy can be monitored by midwives in primary care. We believe that the interpretative/constructivist paradigm as frame of reference is appropriate to our research question. Our study explored the subjective perception of subfertility following assisted conception. We let the parents who have conceived and give birth as a result of fertility treatment speak about delicate issues. To increase the credibility of our findings, we used diverse researchers (investigator-triangulation), a varied group of participants (negative case analysis) and we conducted both individual interviews and interviews with couples letting these two methods complement each other. Particularly delicate topics might be more readily discussed in individual interviews covering maximum depth, whereas for other topics this might be the case in an interview with couples, where there is a more dynamic interaction between the couple and this can generate new ideas or evoke new insights that might not have come up in a one on one interview (data-triangulation). We maintained an audit trail in which we indicate with whom we had a conversation and about what or whether there were any special circumstances. The final subthemes and main themes were discussed in a group session of health care professionals at a conference, and with a midwifery consultant at a fertility centre and with midwifery lecturers (peer debriefing). Participants checked intermittent results of the study (member-checking). Transferability was established through "thick description" [27], in which detailed description of data with a rich mix of participants' quotations were considered. To round off the study, we used the COREQ checklist [29] to ensure that it complied with the criteria for qualitative research.

Despite these strengths, limitations need to be taken into account. The main limitation involves the small sample in which particularly men's perceptions could not be investigated fully. The small number of the joint couple interviews might restrict the impact of the study for the research field. Nevertheless, usable results were obtained that were in agreement with the findings of other authors. Another limitation might be that participants had undergone a wide range of fertility treatments, with no acknowledgements that more invasive forms of treatment or the number of treatment cycles, may have affected the perception of the psychosocial aspect of subfertility. In addition, there 
are disadvantages related to the use of telephone interviews. However, given the wide variety of perceptions captured, we believe that this had no significant influence on the results of this study. Memory biases may have affected the research findings, due to the retrospective nature of the study and the positive pregnancy outcome reached by the participants. The recruitment strategies (through internet forums and snowball sampling) may have also influenced the findings, reaching participants who may be more motivated/comfort Table to share their subfertility experiences. Our study may not add many new insights to what is already known, since there is a considerable body of evidence relating to the psychosocial aspect of childbearing after MAC [23]. Nevertheless, we can focus on how this combined evidence can be translated into tangible messages for midwives and other maternity care providers in community, who might consider pregnancy after MAC as a "normal" pregnancy with no indication for increased risk or extra attention.

Like Gameiro, et al. [37] our study describes psychosocial needs clients experience across their fertility treatment pathway, such as emotional needs (well-being, e.g. anxiety, depression, quality of life) and relational needs (relationship with partner if there is one, family friends and larger network). We did not ask for or found specific behavioural needs (lifestyle, exercise, nutrition and compliance) or cognitive needs (treatment concerns and knowledge).

\subsection{Implications}

Subfertility and fertility treatment are intensive life events that are associated with many different feelings and emotions. It is advisable to take this into account during the antenatal and postnatal care of women who have undergone fertility treatment, and to devote extra time to their emotional well-being during pregnancy and the immediate postnatal period. the theme Emotions during MAC highlight that participants experienced negative emotions but also strong emotional shifts (with positive emotions) at different stages of the subfertility period and a sense of uncontrollability toward the future. As such, primary care midwives may need to provide psycho-education to clients during preconception counselling, about the emotional experience at different stages of the subfertility period, promote realistic expectations toward subfertility treatments and discuss strategies that can help clients to deal with the sense of uncontrollability toward the future. The specificities of each client (namely, the meanings attributed to parenthood) need to be taken into account in clinical practice, because it could influence the subjective experience of subfertility.

Given the importance of social support to our participants, we recommend that midwives and other maternity care providers should check thoroughly whether their clients received sufficient social support during fertility treatment, and whether they are still receiving such support during and after pregnancy. If necessary, the maternity care provider could suggest that clients visit relevant internet forums. Fertility treatment can have various effects on the woman's relationship with her partner and our participants emphasized the involvement of the partner in the treatment. It is therefore advisable for 
the midwife or maternity care provider to also involve the partner in prenatal checks. Couple communication, emotion sharing and shared decision-making can facilitate the psychosocial adjustment of the couples to subfertility period and may be enhanced by healthcare providers. Further prospective research could be aimed at investigating the male experience of subfertility or conducting other joint couple interviews in order to provide an in-depth analysis of couple dynamics/processes and gender issues related to the subfertility period.

\section{Conclusion}

Our study confirms that the feelings and emotions that play such a big role during the subfertile period remain important during pregnancy and even after childbirth. They do not disappear when the woman has achieved her heartfelt ambition of having a baby. It may thus be concluded that fertility treatment has a big impact on people's life. Participants want midwives or other maternity care providers to ask those who successfully achieve pregnancy following fertility treatment about their experiences during fertility treatment, and also want them to check that they still are receiving adequate social support.

\section{Acknowledgements}

The authors are indebted to the participating parents with a history of subfertility and the patient organisation Freya. Furthermore, we would like to thank the students of the Midwifery Academy Groningen group A (Lilian Alberts, Daniëlle Bouma, Simone Brandt and Joske Huitema) for interviewing two couples, and group B (Amanda van der Wal, Irma van der Meer, Annette Zijlstra and Indira Rojer) and group C (Rianke van der Maas, Milou Pijper and Francis Strating) for their earlier contributions on the subject. We would like to thank INholland for receiving the Research award.

\section{Authors' Roles}

$\mathrm{CW}$ originated and supervised the study, was responsible for gaining ethical approval and recruitment of participants. CW interviewed 7 women. JM, NM and CW analysed the data, assisted by SM and MvL and drafted the manuscript. All authors read and corrected draft versions of the manuscript and approved the final manuscript.

\section{Competing Interests}

The authors declare that they have no competing interests.

\section{References}

[1] Boivin, J., Bunting, L., Collins, J.A. and Nygren, K.G. (2007) International Estimates of Infertility Prevalence and Treatment-Seeking: Potential Need and Demand for Infertility Medical Care. Human Reproduction, 22, 1506-1512. https:/doi.org/10.1093/humrep/dem046

[2] Perinatal Registry (PRN Foundation) (2013) Perinatal Cares in the Netherland 2010. The Perinatal Registry, Utrecht. 
[3] College voor Zorgverzekeringen (2003) Obstetric Manual [Verloskundig Vademecum]. College Voorzorgverzekeringen, Diemen.

[4] Paul, M.S., Berger, R., Berlow, N., Rovner-Ferguson, H., Figlerski, L., Gardner, S. and Malave, A.F. (2010) Posttraumatic Growth and Social Support in Individuals with Infertility. Human Reproduction, 25, 133-141. https:/doi.org/10.1093/humrep/dep367

[5] Verhaak, C.M., Smeenk, J.M.J. and Evers, A.W.M. (2007) Women's Emotional Adjustment to IVF: A Systemic Review of 25 Years of Research. Human Reproduction Update, 13, 27 36. https:/doi.org/10.1093/humupd/dml040

[6] Wirtberg, I., Möller, A., Hogström, L., Tronstad, S.-E. and Lalos, A. (2007) Life 20 Years after Insuccessful Infertility Treatment. Human Reproduction, 22, 598-604. https:/doi.org/10.1093/humrep/del401

[7] Tao, P., Coates, R. and Maycock, B. (2012) Investigating Martial Relationships in Infertility: A Systematic Review of Quantitative Studies. Journal of Reproduction \& Infertility, 13, 71 80 .

[8] Péloquin, K. (2013) Infertility: A Social and Spousal Reality That Needs to Be Studied. Integrating Science and Practice, 3, 22-26.

[9] Schmidt, L. (2006) Infertility and Assisted Reproduction in Denmark. Danish Medical Bulletin, 53, 390-417.

[10] Agostini, F., Monti, F., De Pascalis, L., Paterlini, M., La Sala, G.B. and Blickstein, I. (2011) Psychosocial Support for Infertile Couples during Assisted Reproductive Technology Treatment. Fertility \& Sterility, 95, 707-710. https:/doi.org/10.1016/j.fertnstert.2010.06.011

[11] Volgsten, H., Skoog Svanberg, A., Ekselius, L., Lundkvist, O. and Sundström Poromaa, I. (2010) Risk Factors for Psychiatric Disorders in Infertile Women and Men Undergoing in Vitro Fertilization Treatment. Fertility \& Sterility, 93, 1088-1096. https:/doi.org/10.1016/j.fertnstert.2008.11.008

[12] Fisher, J.R. and Hammarberg, K. (2012) Psychological and Social Aspects of Infertility in Men: An Overview of the Evidence and Implications for Psychologically Informed Clinical Care and Future Research. Asian Journal of Andrology, 14, 121-129. https:/doi.org/10.1038/aja.2011.72

[13] Pasch, A.L., Dunkel-Schetter, C. and Christensen, A. (2002) Differences between Husbands' and Wives' Approach to Infertility Affect Marital Communication and Adjustment. Fertility \& Sterility, 77, 1241-1247. https:/doi.org/10.1016/S0015-0282(02)03097-2

[14] Chachamovich, J.R., Chachamovich, E., Ezer, H., Fleck, M.P., Knauth, D. and Passos, E.P. (2010) Investigating Quality of Life and Health-Related Quality of Life in Infertility: A Systematic Review. Journal of Psychosomatic Obstetrics and Gynaecology, 31, 101-110. https:/doi.org/10.3109/0167482X.2010.481337

[15] Martins, M.V., Peterson, B.D., Almeida, V., Mesquita-Guimarães, J. and Costa, M.E. (2014) Dyadic Dynamics of Perceived Social Support in Couples Facing Infertility. Human Reproduction, 29, 83-89. https:/doi.org/10.1093/humrep/det403

[16] Younger, M., Hollins-Martin, C. and Choucri, L. (2015) Individualised Care for Women with Assisted Conception Pregnancies and Midwifery Practice Implications: An Analysis of the Existing Research and Current Practice. Midwifery, 31, 265-270. http://dx.doi.org/10.1016/j.midw.2014.06.008

[17] Gameiro, S., Moura-Ramos, M., Canavarro, M.C. and Soares, I. (2010) Psychosocial Adjustment during the Transition to Parenthood of Portuguese Couples Who Conceived Spontaneously or through Assisted Reproductive Technologies. Research in Nursing \& Health, 33, 207-220. 
[18] Hjelmstedt, A., Widström, A.-M., Wramsby, H. and Collins, A. (2003) Patterns of Emotional Responses to Pregnancy, Experience of Pregnancy and Attitudes to Parenthood among IVF Couples: A Longitudinal Study. Journal of Psychosomatic Obstetrics and Gynaecology, 24, 153-162. http://dx.doi.org/10.3109/01674820309039669

[19] Kremer, J., Wiersma, T.J., Breejen den, E., Knijnenburg, J., Nelen, W.L.D.M., et al. (2010) [Landelijke Netwerkrichtlijn Subfertiliteit]. NVOG.

[20] Papaharitou, S., Nakopoulou, E. and Moraitou, M. (2010) Assisted Reproduction and Midwives: Student and Certified Midwives Educational Needs on Reproductive Biology. Sexual and Reproductive Healthcare, 1, 163-168. http://dx.doi.org/10.1016/j.srhc.2010.07.002

[21] Allan, H. and Finnerty, G. (2007) The Practice Gap in the Care of Women Following Successful Infertility Treatments: Unasked Research Questions in Midwifery and Nursing. Human Fertility, 10, 99-104. http://dx.doi.org/10.1080/14647270601050320

[22] Allan, H. and Finnerty, G. (2009) Motherhood Following Successful Infertility Treatment. In: Hunter, B. and Deery, R., Eds., Emotion in Midwifery and Reproduction, Part II: Emotion Work and Infertility, the Lavenham Press, Suffolk, 125-139.

[23] ESHRE Psychology and Counselling Guideline Development Group (2015) Routine Psychosocial Care in Infertility and Medically Assisted Reproduction-A Guide for Fertility Staff.

[24] Warmelink, J.C., Adema, W., Pranger, A. and de Cock, T.P. (2015) Client Perspectives of Midwifery Care in the Transition from Subfertility to Parenthood-A Qualitative Study. Journal of Psychosomatic Obstetrics and Gynaecology, 37, 1-9.

[25] Barnes, M., Roiko, A., Reed, R., Williams, C. and Willcocks, K. (2012) Outcomes for Women and Infants Following Assisted Conception: Implications for Perinatal Education, Care, and Support. The Journal of Perinatal Education, 21, 18-23. http://dx.doi.org/10.1891/1058-1243.21.1.18

[26] Redshaw, M., Hockley, C. and Davidson, L.L. (2007) A Qualitative Study of the Experience of Treatment for Infertility among Women Who Successfully Became Pregnant. Human Reproduction, 22, 295-304. http://dx.doi.org/10.1093/humrep/del344

[27] Baarda, B. (2014) Research. This Is It! Guidelines How to Design, Perform and Evaluate Quantitative and Qualitative Research. Noordhoff Uitgevers Bv, Groningen.

[28] Mackenzie, N. and Knipe, S. (2006) Research Dilemmas: Paradigms, Methods and Methodology. Issues in Educational Research, 16, 193-205.

[29] Tong, A., Sainsbury, P. and Craig, J. (2007) Consolidated Criteria for Reporting Qualitative Research (COREQ). International Journal for Quality in Health Care, 19, 349-357. http://dx.doi.org/10.1093/intqhc/mzm042

[30] Boivin, J., Griffiths, E. and Venetis, C.A. (2011) Emotional Distress in Infertile Women and Failure of Assisted Reproductive Technologies: Meta-Analysis of Prospective Psychosocial Studies. British Medical Journal, 342, d223. http://dx.doi.org/10.1136/bmj.d223

[31] Domar, A., Gordon, K., Garcia-Velasco, J., La Marca, A., Barriere, P and Beligotti, F. (2012) Understanding the Perceptions of and Emotional Barriers to Infertility Treatment: A Survey in Four European Countries. Human Reproduction, 27, 1073-1079. http://dx.doi.org/10.1093/humrep/des016

[32] Klemetti, R., Raitanen, J., Sihvo, S., Saarni, S. and Koponen, P. (2010) Infertility, Mental Disorders and Well-Being-A Nationwide Survey. Acta Obstetriciaet Gynecologica, 89, 677-682. http://dx.doi.org/10.3109/00016341003623746

[33] Greil, A.L., Slauson-Blevins, K. and McQuillan, J. (2010) The Experience of Infertility: A Review of Recent Literature. Sociology of Health \& Illness, 32, 140-162. 
http://dx.doi.org/10.1111/j.1467-9566.2009.01213.x

[34] Wilkes, S., Hall, N., Crosland, A., Murdoch, A. and Rubin, G. (2009) Patients Experience of Infertility Management in Primary Care: An In-Depth Interview Study. Family Practice, 26, 309-316. http://dx.doi.org/10.1093/fampra/cmp039

[35] Martins, M.V., Peterson, B.D., Almeida, V.M. and Costa, M.E. (2011) Direct and Indirect Effects of Perceived Social Support on Women's Infertility-Related Stress. Human Reproduction, 26, 2113-2121. http://dx.doi.org/10.1093/humrep/der157

[36] Klock, S. (2011) Psychological Issues Related to Infertility. The Global Library Women's Medicine.

[37] Gameiro, S., Boivin, J., Dancet, E., Emery, M., Thorn, P., Van den Broeck, U., Venetis, C., Verhaak, C.M., Wischmann, T. and Vermeulen, N. (2016) Qualitative Research in the ESHRE Guideline Routine Psychosocial Care in Infertility and Medically Assisted Reproduction-A Guide for Staff. Guideline Development Group of the ESHRE Guideline on Psychosocial Care in Infertility and Medically Assisted Reproduction. Human Reproduction, 31, 1928-1929. http://dx.doi.org/10.1093/humrep/dew155

\section{Submit or recommend next manuscript to SCIRP and we will provide best service} for you:

Accepting pre-submission inquiries through Email, Facebook, LinkedIn, Twitter, etc.

A wide selection of journals (inclusive of 9 subjects, more than 200 journals)

Providing 24-hour high-quality service

User-friendly online submission system

Fair and swift peer-review system

Efficient typesetting and proofreading procedure

Display of the result of downloads and visits, as well as the number of cited articles

Maximum dissemination of your research work

Submit your manuscript at: http://papersubmission.scirp.org/

Or contact ojog@scirp.org 